\title{
O MOBRAL E A EDUCAÇÃO DE CRIANÇAS MENORES DE SEIS ANOS DURANTE O REGIME MILITAR: EM DEFESA DO TRABALHO VOLUNTÁRIO
}

\author{
Alessandra ArCE*
}

\begin{abstract}
Ser Monitor:/Apesar de nem sempre ter tudo,/Faltar tanto para o que quero fazer;/O que importa é a vontade, é o sonho,/É aquilo que quero obter.../É olhar para as minhas crianças/E com elas cantar e brincar.../É esperar que descubram, sozinhas, /As belezas do céu, dessa terra e do mar.../É saber que as estou ajudando/A crescer, conviver e amar.../É vibrar junto a elas, contente,/Quando sinto que as faço pensar.../É saber que assim estou tentando,/ Minha gente, ser grande, ser forte,/E esta terra que é minha, que é sua,/Meu trabalho, que sei é pequeno,/Vai contudo ajudar a mudar/E estou certo, eu creio, acredito,/Muitas vidas eu vou melhorar! (Yara P. M. de Faria, revista Criança, 1982).
\end{abstract}

RESUMO: Este artigo propõe-se a realizar uma reflexão sobre a imagem divulgada durante o período militar no Brasil a respeito da pessoa que trabalhava com as crianças menores de seis anos. Este trabalho utiliza, para tanto, os manuais produzidos pelo Movimento Brasileiro de Alfabetização (MOBRAL) destinados a este nível de educação. Eis os pontos destacados: psicologização do atendimento; desprezo pela formação teórica em detrimento da prática; defesa do trabalho voluntário; indefinição da especificidade deste nível de atendimento educacional.

Palavras-chave: Política educacional. MOBRAL. Educação infantil.

\footnotetext{
* Doutora em Educação Escolar e professora do Centro de Educação e Ciências Humanas da Universidade Federal de São Carlos (UFSCAR). E-mail: alessandra.arce@uol.com.br
} 
O mobral e a educação de crianças menores de seis anos durante o regime militar...

MOBRAL AND THE EDUCATION OF CHILDREN UNDER 6 UNDER THE MILITARY REGIME: A DEFENSE OF VOLUNTEER WORK

ABSTRACT: This article debates early childhood education during the dictatorship in Brazil. To do so, it analyzes documents from the MOBRAL (Brazilian Literacy Movement). As a result, it explores the following issues: psychology having a leading role in teacher's education; theoretical versus practical approach; voluntary work instead of professional education for future teachers.

Key words: Educational policy. MOBRAL. Early childhood education.

\section{Introdução}

$E$

ste artigo apresenta-se como um exercício de reflexão a respeito da imagem divulgada, durante o período da ditadura militar no Brasil, da pessoa que deveria trabalhar com crianças menores de seis anos. Este trabalho utiliza, para tanto, os manuais produzidos pelo Movimento Brasileiro de Alfabetização (MOBRAL) destinados a este nível de educação. Parte-se da premissa de que a definição dada a esta pessoa durante o período trouxe resultados nefastos para a construção do perfil profissional do docente que atua com esta faixa-etária, fato este que se perpetua até a atualidade.

Durante a década de 1980 , o MOBRAL ${ }^{1}$ figurou como responsável pela educação de crianças menores de seis anos no Brasil, realizando o processo de expansão deste tipo de atendimento por todo o território nacional. A utilização de recursos da comunidade e o voluntarismo, marcas do trabalho do MOBRAL com a educação de adultos, acabaram por encontrar na educação infantil um terreno fértil para a cristalização das mesmas. Desde o final da década de 1960, o Ministério da Educação e Cultura (MEC) vinha, em seus documentos, adotando as marcas fundamentais do MOBRAL. Passar a educação infantil para as mãos do mesmo tornaria a sua expansão mais rápida e barata, respondendo assim aos anseios populares por este tipo de atendimento. Nossas fontes de análise foram os documentos expedidos pelo MOBRAL destinados aos professores de educação infantil, incluindo-se aqui o periódico $A$ Criança, editado pelo mesmo de 1980 a 1988 (trabalhamos com dois números do periódico por ano). 
A epígrafe deste artigo foi retirada de um encarte do primeiro número da revista Criança, publicada pelo mOBRAL (de 1982 a 1988), época em que este órgão atendia a educação pré-escolar no Brasil. As palavras expressas no folheto trazem um enorme apelo ao passional, à emoção, ao amor maternal, quase que tornando-o uma oração para que todo o trabalho amoroso realizado pela pessoa que atua com as crianças dê certo. Esta pessoa aqui definida, no interior da revista, como "monitor", apesar de possuir o vocábulo no masculino, recebe um texto extremamente ligado ao que se convencionou associar ao gênero feminino: emotividade, meiguice, amor maternal. $O$ presente encarte foi colocado no início deste artigo, como ilustração da discussão que travarei no decorrer do mesmo e do discurso presente no conjunto dos documentos aqui apresentados. Para além do esteriótipo feminino, encontrar-se-á exposta nessas páginas a defesa do espontaneismo, presente na precariedade do trabalho desenvolvido com as criança menores de seis anos sob os cuidados do monitor.

Gostaria de destacar que este trabalho coloca-se em oposição às correntes pós-modernas que têm invadido a historiografia e, muitas vezes, levado a uma confusão entre fato histórico e ficção. Hobsbawn (1998) descreve muito bem este processo, quando afirma que a mistura de literatura e antropologia nos estudos históricos tem levado à defesa de que não existe objetividade nos fatos estudados pelo historiador, os mesmos não passariam de construções intelectuais, o que vem descaracterizando o aspecto político que a história possui, dando a falsa impressão de que a mesma não passa de mera descrição de pontos de vistas diferentes a respeito de algo que aconteceu.

Ora, a história é a matéria-prima para as ideologias nacionalistas ou étnicas ou fundamentalistas, tal como as papoulas são a matéria prima para o vício da heroína. O passado é um elemento essencial, talvez, o elemento essencial nessas ideologias. Se não há nenhum passado satisfatório, sempre é possível inventá-lo. (Hobsbawn, 1998, p. 17)

Portanto, a adoção de pesquisas que transformam a historiografia numa infinita gama de releituras, re-significações sem qualquer possibilidade de verificação sobre o grau maior ou menor de verdade de cada uma delas, não é inofensiva, ela tem difundido e fortalecido um posicionamento ideológico que visa combater todos aqueles que 
O mobral e a educação de crianças menores de seis anos durante o regime militar...

defendam a possibilidade de conhecimento objetivo da história e dos laços existentes entre as ideologias e as relações sociais, objetivamente existentes entre os homens, no interior de um modo de produção historicamente constituído. Opera-se uma verdadeira guerra, na qual se busca acabar com a história, transformando-a em história de particularidades, das curiosidades, soltas no mundo e podendo ser lidas e interpretadas de mil maneiras diferentes (como as chamadas histórias das mentalidades, histórias da vida privada). A busca pela verdade sai de cena e o terreno se torna fértil para os mitos e para a invenção, propagando mais ignorância e misticismo, numa posição claramente contrária à razão e propagadora do irracionalismo que tanto apraz aos pósmodernos. Esse fato instaura o relativismo, mas, como o autor afirma, tais preceitos não são levados a suas últimas conseqüências quando estão em jogo os interesses que dominam a nossa sociedade. A atividade de quem se propõe a trabalhar com história é a de desmantelar as mitologias, não se tornar servo dos ideólogos do poder, fornecendo munição para a acusação, mas sim retirar vendas que são usadas como mitos de justificação das relações capitalistas, as quais se procura sempre naturalizar, eternizar.

Entende-se, nesse trabalho, que ao estudar-se um conjunto de documentos, os compreendemos, os analizamos como frutos de síntese das múltiplas determinaçôes sociais de sua época histórica, o que permite a apreensão de um conjunto de idéias e ideais presentes na mesma. Permite-se, assim, olhar o local sem disvinculá-lo do âmbito da totalidade; assim, o material documental desvela-se como objeto privilegiado para olhar a sociedade e suas práticas em um determinado momento histórico. Desnudam-se as unidades de ação, revelando os objetos e finalidades perseguidos pelos homens que as idealizaram. Realiza-se, nesse pequeno artigo, o exercício que Vainfas (2002, p. 150) chamou de alternância de escalas na pesquisa em história, ou seja, "uma passagem do olhar macrossocial para a observação microanalítica com procedimento metodológico, sem prejuízo da primeira”. Busca-se, portanto, desvelar o que está "(...) À sombra do panteão das histórias nacionais ou oficiais. À sombra das mitologias, ideologias e religiōes”. (idem, ibid., p. 142). Cabe ressalvar que nessa busca compreende-se que as instituições e suas produções documentais, concordando com Saviani (2007), são criações para a satisfação de necessidades humanas. 
Necessidades sempre em mudança, constantemente manifestando-se, revelando o conjunto de relações travadas pelos atores sociais que as criaram, modificaram e as mantêm. Consequentemente, o historiador não pode contentar-se com visões particularizadas, fragmentadas e superficiais do cotidiano e das instituiçôes. Ele deve inserir-se no contexto mais amplo, onde o micro e o macro se entrelaçam. "O quotidiano só tem valor histórico e científico no seio de uma análise dos sistemas históricos, que contribuem para explicar o seu funcionamento" (Le Goff, 1994, p. 93).

Objetivando debater a premissa inicial do artigo, o subdividimos em duas partes: a primeira apresenta o discurso encontrado nos documentos MOBRAL e a segunda procura apontar as conseqüências advindas da efetivação da imagem difundida nos documentos na carreira do docente de crianças menores de seis anos, no Brasil.

\section{O MOBRAL e a educação de crianças menores de seis anos no Brasil}

De 1982 a $1985^{2}$ o MOBRAL encaixou-se, por seu trabalho sempre realizado com o auxílio da comunidade, no perfil do órgão ideal para cuidar da expansão do atendimento pré-escolar, defendida no III Plano Setorial de Educação Cultura e Desporto (PSECD), ${ }^{3}$ cuja tônica voltava-se para a mobilização da comunidade e uso dos recursos locais. O MOBRAL foi responsável pela expansão da pré-escola no Brasil, chegando em 1982 a responder por 50\% do atendimento pré-escolar público. $\mathrm{O}$ atendimento restringia-se a crianças de 4 a 6 anos e a política do MEC, já descrita, guiava o cotidiano das instituições educacionais destinadas a essa faixa-etária.

Durante a época em que se dedicou à educação pré-escolar, o MOBRAL enfatizou o treinamento em serviço da pessoa que deveria atuar com as crianças (o monitor), em detrimento de uma formação teórica e metodológica densa, em cursos de formação em nível de segundo e terceiro graus. As principais fontes para os treinamentos foram materiais didáticos produzidos pelo próprio MOBRAL. Entre eles, destacam-se o livro Vivendo a pré-escola, a revista Criança e o conjunto de cadernos intitulados "Temas para Reflexão". Todo o material produzido pelo MOBRAL destinado ao monitor era marcado pelas Diretrizes do MEC de $1980,{ }^{4}$ com incentivo ao voluntarismo e treinamento em serviço, por 
O mobral e a educação de crianças menores de seis anos durante o regime militar...

meio da distribuição de manuais. Destaca-se, ainda, a sintonia existente entre a documentação e o estabelecido pelo III PSECD, ${ }^{5}$ que define para o pré-escolar as seguintes formas de ação:

- Integrar as ações educativo-culturais com outras iniciativas de política social voltadas para o menor, notadamente as de saúde, saneamento e nutrição, de melhoria das condições habitacionais e de organização social;

- Mobilizar os meios comunitários e os recursos locais, potencializando a educação familiar pelo envolvimento de todos os seus membros em processos educativos comuns, sem discriminação de idade;

- Enfatizar a adoção de inovações metodológicas que permitam desformalizar os processos educativos prévios à escolarização, integrando-os ao desenvolvimento cultural das populações envolvidas. (Brasil, 1983, p. 15; grifos meus)

Dessa maneira, as ações estabelecidas no III PSECD casavam com a forma como o MOBRAL conduzia a educação de jovens e adultos, caracterizando-se como uma continuidade de trabalho e economizando-se tempo para sua execução. Contudo, estes documentos carregaram, ainda mescladas a estes preceitos, as discussões que a academia vinha empreendendo nesta época a respeito de como deveria ser este tipo de educação. ${ }^{6}$ Esta ambigüidade de discurso estará presente a todo momento. Entretanto, prevaleciam os preceitos contidos nas citadas Diretrizes do MEC. Alia-se a este discurso ambíguo a deficiente interpretação que se fará das teorias da psicologia do desenvolvimento nestes manuais. Este fato acabava por reforçar o discurso de que os interesses e necessidades das crianças são suficientes para o monitor realizar seu trabalho, dando margem para a realização de atividades de cunho espontaneísta, sem considerar a necessidade de aprofundamento do conhecimento que a criança possui. $\mathrm{O}$ trabalho educativo, portanto, não era concebido como aquele que deve paulatinamente levar a criança à superação do senso comum e ao reconhecimento do saber científico por incorporação do mesmo a sua vida cotidiana. A formação insuficiente do monitor e o ambiente que primava pela antiprofissionalização, expresso em seu apelo voluntarista, tornavam bastante problemática a 
condução do processo educativo. Mas como os documentos apresentam esse discurso?

O primeiro documento, Vivendo a pré-escola, foi lançado em 1982, com o objetivo de facilitar o dia-a-dia das pessoas que atuassem com crianças menores de 6 anos, definidas aqui como "monitores". O documento é subdividido da seguinte forma: I - A criança e seu desenvolvimento; II - O monitor e as crianças; III - O monitor e as famílias; IV - Dinâmica de trabalho do monitor; V - Atividades na pré-escola; VI - Materiais e VII - Algumas técnicas de desenho, pintura, recorte, colagem e modelagem. A linguagem utilizada no manual é simples e de fácil entendimento. É dispensada maior atenção ao tema referente ao desenvolvimento infantil, não ficando claro qual quadro teórico serve de base para o mesmo, sendo citados conceitos de Celèstin Freinet, Jean Piaget, Paulo Freire e Constance Kamii. Ainda no item $A$ criança e seu desenvolvimento, o conceito de desenvolvimento humano aparece como algo linear, ou seja, enfatizam-se as fases nesse processo, caracterizando-as por um processo semelhante à maturação dos organismos biológicos. Procura-se levar o monitor a compreeder que o desenvolvimento é global, dinâmico e marcado por estágios, apresentados como blocos a nortear o olhar do mesmo sobre a criança. No texto, entretanto, há um destaque grande para o papel da afetividade:

Permeando todo o processo de desenvolvimento infantil, que é global, está a afetividade, ou seja, a relação de amor, carinho, enfim, os sentimentos que se estabelecem naturalmente entre as pessoas. A afetividade fornece a energia necessária para que a criança possa se desenvolver. (MOBRAL, 1982, p. 12)

Ninguém negaria a importância da afetividade. Entretanto, no contexto do manual ela ganha um status de fonte do desenvolvimento, fato este que não é consenso entre as diversas teorias que existem a respeito do desenvolvimento psiquico infantil. Ao final do item, apresenta-se ao monitor um diagrama com os principais passos a serem observados no desenvolvimento e em que momento eles aparecem na criança. Apenas para exemplificar: o bebê apresenta - movimentos reflexos, chora, suga, emite sons e depende do adulto. O desenvolvimento, no diagrama, apresenta-se cindido nos seguintes eixos: a criança e os movimentos, a criança e os objetos, a criança e a socialização e a 
O mobral e a educação de crianças menores de seis anos durante o regime militar...

criança e a comunicação. Este tipo de definição do desenvolvimento infantil é temeroso, pois, às pessoas com pouca ou nenhuma formação, ele acaba por servir como um receituário, tomando por naturais definições do desenvolvimento que não o são. Ao tornar-se uma receita, revela-se nefasta para a criança, levando o profissional à busca pelo encaixe do indivíduo no modelo. $\mathrm{O}$ resultado final dessa equação: desenvolvimento infantil naturalizado + receituário + pouca formação $=$ preconceito e práticas excludentes no cotidiano das instituições.

Ao ler o item II, $O$ monitor e as crianças, a concepção naturalizante de desenvolvimento torna-se mais clara logo no primeiro parágrafo, com a seguinte afirmação:

O seu objetivo, monitor, é o de promover o desenvolvimento das crianças, partindo dos interesses e necessidades delas. Observando suas brincadeiras e jogos, as músicas que gostam de cantar, as tarefas que realizam, você vai tomando conhecimento de como são, do que gostam e do que não gostam. Também as condições de vida na comunidade influenciam na maneira como elas se comportam. Essas condiçōes dizem respeito à alimentação, à saúde, à moradia, ao trabalho, aos recursos disponíveis etc. (Idem, ibid., p. 17)

O excerto acima reune não só a idéia de que o adulto que está com a criança tem como uma de suas funções principais a de observador e de acompanhante do processo de desenvolvimento, mas também traz implícita a idéia de que a socialização passa pelo compartilhar das condiçôes e dos aprendizados pertencentes à esfera da comunidade. Consequentemente, o socializar acaba por reduzir-se ao simples estar junto, ao brincar junto, e a figura do adulto e da transmissão cultural atenuam-se. Assim, não só o desenvolvimento é tomado como algo natural, bastaria guardá-lo para acontecer, como também o processo de construção do pertencimento da criança ao gênero humano.

A ênfase no trabalho comunitário aparece, para o monitor, quando se determina que a comunidade deve ser fonte de conhecimentos para as crianças, reduz-se o universo e os conhecimentos, pois, ao tomarmos como ponto de partida e chegada o cotidiano expresso na comunidade, reduzimos o espectro de contato da criança e, consequentemente, estreitamos o seu universo de conhecimento. De forma alguma, pela afirmação anterior, faz-se a defesa de que o conhecimento proveniente da comunidade na qual a criança está 
inserida deva se descartado. Sua incorporação é necessária. Entretanto, esse conhecimento é o ponto de partida. Como meta para a chegada do trabalho educativo deve-se tomar o conjunto dos conhecimentos científicos e artísticos produzidos pela humanidade.

Esse mundo que rodeia as crianças - seus amigos, você, a unidade de pré-escolar, a comunidade - é uma fonte de conhecimentos práticos que elas podem descobrir e adquirir, através da própria vivência. Assim, é importante que sejam propostas atividades que favoreçam a exploração do ambiente em que vivem. (Idem, ibid.)

O incentivo ao envolvimento da comunidade ${ }^{7}$ é o principal, tanto que os pais devem ser chamados para dentro da escola, mas não com o intuito de discutir o tipo de educação dada para seus filhos, mas no sentido de trabalhar com o professor, dividindo com ele a sala de aula. A defesa da presença de membros da comunidade é tão forte que se aconselhava e se recrutavam monitores, de preferência da mesma, dando-se prioridade a uma mãe ou voluntária. Acentua-se, nessa chamada da comunidade, o caráter de improvisação deste atendimento. $\mathrm{Na}$ verdade, a comunidade com ou sem condiçõos acabava por assumir a educação de suas crianças.

Além disso, nesses encontros, você provavelmente terá a oportunidade de conhecer pessoas que possuam alguma habilidade que interesse às crianças. Por exemplo, alguém que saiba contar histórias da comunidade, um sanfoneiro, um artesão e etc. Você, então, pode aproveitar e convidálos para desenvolver essas atividades com as crianças. Desta forma, você estará não só valorizando a comunidade, como também ampliando as experiências das crianças, partindo da cultura local. (Idem, ibid., p. 25)

Não há definição curricular para o trabalho e é grande a ênfase na confecção de materiais e receituário de atividades. O grande elemento norteador deste documento reside no simples delegar à criança todos os poderes e deveres da educação, o que remete o monitor a uma figura insignificante, enfim, incapaz de raciocinar, de decidir sozinho a respeito de algo. Apesar do vocábulo "monitor" encontrar-se no masculino, todos os desenhos do livro mostram apenas mulheres exercendo esta função. Nem o direito de ter uma nomenclatura que represente o gênero feminino atuante nesta educação esta mulher possuía. A incapacidade de raciocinar conceitualmente é acentuada 
O mobral e a educação de crianças menores de seis anos durante o regime militar...

neste documento de maneira muito dura, e a mulher-coração, sensível, que possui bom senso acima de tudo, é idolatrada. Responsabilizar as crianças pelo processo é também uma forma de disfarçar o despreparo, o trabalho voluntário e a falta de formação desta monitora que, sem experiência profissional, seria incapaz de realizar um trabalho mais apropriado e que transcendesse as barreiras do senso comum. Sem embargo, operar essa inversão no processo de ensino-aprendizagem desvela a precariedade o trabalho pedagógico realizado. A posição de inferioridade a que este documento remete a monitora define, de forma clara, como não-profissional o trabalho exercido, acentuando o guardar apenas e o cuidar tal como se faz com os filhos em casa. O regime militar expandia o atendimento a crianças pequenas no Brasil, respondendo aos anseios e reivindicações da mulheres brasileiras, mas o fazia tendo o baixo custo como sua bandeira. Consequentemente, como educação de qualidade não se faz de forma barata, ao invés de encontrar uma instituição preparada para atender nossas crianças, deparava-se como uma situação excludente ao extremo, escamoteada no discurso da inclusão.

Logo após a publicação do Vivendo a pré-escola", o MOBRAL editou três cadernos destinados à capacitação dos monitores, os quais reforçavam os preceitos descritos no documento anteriormente apresentado. Estes documentos chamam-se "Temas para reflexão", sendo cada um dedicado a um tema em especial. Os cadernos seguiam o padrão de manual, possuindo, ao final de cada texto, uma folha destinada ao monitor para que esse descrevesse como fez o estudo e quais as dúvidas e sugestôes surgidas no decorrer da leitura.

O primeiro tema para reflexão foi intitulado "Educação". Neste volume, são apresentadas as razões que levaram o MOBRAL a assumir o atendimento educacional ao pré-escolar e quais as funções que este tipo de atendimento vinha recebendo. Contudo, dentre as diversas funções destaca-se a pedagógica, que deverá nortear o trabalho do monitor. Ao definir como o MOBRAL passou a cuidar do atendimento educacional ao pré-escolar, o documento apresenta quais deveriam ser os pontos de partida do monitor para realizar o seu trabalho, a ênfase na comunidade aparece, a educação das crianças menores de seis anos cristaliza-se a cada manual como centrada no âmbito comunitário. 
A partir daí, o MOBRAL passou a desenvolver uma ação educativa com a pré-escola, envolvendo famílias, comunidades, monitores e voluntários, tomando como ponto de partida:

- o que as famílias das crianças já conhecem, sabem e ensinam a seus filhos;

- sua maneira de falar, de trabalhar, de se divertir, de pensar;

- as músicas, danças, histórias que conhecem;

- aquilo em que acreditam e consideram importante.

Enfim, essa ação foi pensada com base na educação dada às crianças por seus pais e presente no seu dia-a-dia. (MOBRAL, 1983, p. 13)

Em seguida, o documento passa a apresentar as funções que a pré-escola recebeu no decorrer de sua história, destacando: pré-escola como supridora das carências infantis, pré-escola como forma de garantir que a criança viva plenamente a sua infância, pré-escola como formadora de hábitos e atitudes necessárias para a vida das crianças em sociedade. $\mathrm{O}$ documento destaca o que deverá dar sentido ao trabalho do monitor: a função pedagógica. Todavia, não faz críticas e nem se opõe às demais. Assim sendo, não se esclarece o porquê da escolha dessa em detrimento das outras.

Significa que cabe à pré-escola transmitir às crianças conhecimentos e habilidades que servirão para sua futura vida escolar. Esses conhecimentos (descobertas que fazem, experiências que vivem, noções que adquirem) vão facilitar-lhes o domínio da leitura, da escrita e do cálculo. (MOBRAL, 1983, p. 20)

A função pedagógica definida pelo MOBRAL aparece muito próxima da preparatória para as séries posteriores, pois escolhem-se habilidades e conhecimentos pensando-se na sua utilidade para a futura vida escolar da criança. Mas que habilidades e conhecimentos são estes o documento não explicita, nem chega a delinear um caminho. Questionamos como este monitor, exercendo trabalho voluntário, geralmente uma mãe da comunidade ou alguém que mal possuía o primeiro grau completo, poderia trabalhar esta função pedagógica. Isto ocorreria com base apenas em seu bom senso e capacitação feita por manuais e receituários? 
O mobral e a educação de crianças menores de seis anos durante o regime militar...

É preciso, então, que as atividades da pré-escola tenham intencionalidade: o monitor precisa saber por que está propondo cada situação. É muito importante, também, que cada atividade se relacione com as outras, de uma maneira viva e com bastante significado para as crianças. (MOBRAL, 1983, p. 22)

Que atividade são estas? Como o monitor saberá os porquês das atividades que está propondo? São questões não respondidas por este documento, mas que podem ser respondidas quando se consultam outros documentos do MOBRAL. A primeira questão aqui exposta pode ser respondida através do Vivendo a pré-escola, no qual as atividades resumiam-se à confecção de jogos, brincadeiras, músicas, técnicas de desenho, modelagem etc., enfim, um receituário de técnicas sem a explicação do porquê de sua aplicação. Vê-se um centramento no trabalho manual na formação das crianças nessas atividades. A segunda questão, bem, esta fica sem resposta, pois como esta pessoa poderá fazer escolhas em que ela revele sua competência teórica e prática se lhe obliteram a reflexão teórica, ao fornecer-lhe apenas um conjunto de conceitos inacabados, retirados, na maioria das vezes, de uma miscelânea teórica e apresentados como suficientes, prontos e definitivos?

O segundo tema para a reflexão tem como eixo a ação comunitária: "Ação comunitária a partir de uma unidade pré-escolar - a participação da família”. Neste documento a comunidade volta a ser a tônica principal do atendimento, reforça-se a idéia de que a educação adequada a ser dada para a criança deve estar inserida no meio em que ela vive, na sua cultura. Justifica-se a partir deste ponto o porquê da comunidade contribuir neste atendimento, com voluntários, serviços, local para realização do atendimento etc. Dá-se uma enorme importância à comunidade, de tal forma que se acaba por ocultar a verdadeira razão de sua participação tão efetiva. Quando a comunidade assume o atendimento, o governo barateia ou zera os custos deste, delegando responsabilidades, expande o sistema com um atendimento de baixa qualidade e barato, o que se justifica como o ideal no discurso do MOBRAL, pois a educação adequada deve estar baseada no meio em que a criança vive.

O programa pré-escolar, estando aberto para as pessoas e para a mobilização de recursos comunitários, vai, logicamente, respeitar os valores, os hábitos e as maneiras de a comunidade se organizar, se dividir. Nosso 
objetivo aqui é conversar um pouco sobre a importância que essa aproximação comunidade/unidade tem para as pessoas interessadas no programa. E, também, como você, monitor, deve agir para conseguir e solidificar essa aproximação. (MOBRAL, 1983, p. 6)

A chamada da comunidade para o atendimento, principalmente dos pais, reforça o exposto, tornando os mesmos marceneiros, pedreiros da escola, entre outros, ou até mesmo monitores voluntários da mesma. O documento afirma este fato a todo instante e insiste que o monitor deve reforçar esta "participação", pois será ótimo para ele e até mesmo para as suas aulas. A finalização da argumentação, com o termo "benefício para as crianças", faz todo sacrifício valer a pena, tanto para pais como para os monitores.

Além disso, à medida que os pais se aproximam mais, passam a conhecer e a se interessar pelos problemas que você enfrenta e podem ajudar a tomar decisões e a encontrar soluções não só como consertar uma mesa quebrada, serrar os pés de cadeira alta, ajudar no preparo da merenda, ajudar na organização de uma festa, participar de um passeio com as crianças, como também organizar comissões para buscar algum recurso comunitário, decidir o que fazer com a verba que o MOBRAL envia. (MOBRAL, 1983, p. 10)

Além desta ênfase ao informalismo, ao amadorismo no atendimento, o documento ainda afirma que, para o monitor trabalhar com suas crianças, deve mergulhar na vida da comunidade, pois assim passará "a dividir sua responsabilidade com os pais, discutindo, trocando idéias, solucionando os problemas, trabalhando juntos" (idem, ibid., p. 14). O monitor torna-se refém, assim como o processo de ensinoaprendizagem da comunidade, os conteúdos a serem trabalhados devem ser por ele pinçados dos problemas da comunidade e neles se alicerçar. Privilegia-se, portanto, o micro, o local do cotidiano, e abandona-se o macro, a totalidade, tudo o que está para além do dia-a-dia das crianças e suas famílias.

Por isso, é importante que você procure, aos poucos, conhecer:

- os problemas mais sentidos pela vizinhança da sua unidade;

- os grupos comunitários e as entidades cujas atividades e serviços podem contribuir para diminuir os problemas das crianças de sua unidade; 
O mobral e a educação de crianças menores de seis anos durante o regime militar...

- os programas do MOBRAL, cuja implantação existe no local, podem contribuir para ajudar as famílias das crianças. (Idem, ibid., p. 19)

A pré-escola passa quase que a se caracterizar como um "centro comunitário", distanciando-se cada vez mais de uma escola, e as pessoas que atendem as crianças, da figura de profissionais, docentes. O terceiro caderno, "Saúde e higiene", traz para o monitor um receituário de como proceder à frente das principais doenças infantis, da premência de efetuar primeiros socorros, carregando ainda muito da visão deixada pela década de 1970, quando o tripé do atendimento na pré-escola estava sobre: saúde, educação, nutrição/higiene. Estes cadernos reforçam toda a discussão esboçada até este momento, um atendimento amador, de qualidade questionável, centrado na comunidade, a qual deve ser responsável pelo mesmo. Prima-se pela defesa do trabalho voluntário, cuja pessoa a realizar este tipo de atendimento necessita apenas de receitas e manuais inacabados. Assim, como afirma o Parecer do MEC n. 1600/75 (Brasil, 1979), ele não deve ensinar, mas oportunizar, portanto, não necessitando de uma formação sólida, apenas alguns passos para seguir. A não-profissionalização, que acaba por incentivar o voluntarismo, tão apelada e reafirmada no "Programa Nacional de Educação Pré-Escolar" de 1980, é real, o que torna todo este material extremamente coerente com as políticas de não-formação da pessoa a atuar em instituições educacionais com crianças menores de seis anos.

A publicação Criança, do MEC e MOBRAL, iniciou-se em 1982 na forma de informativo, com o objetivo de contribuir para o aperfeiçoamento do trabalho do monitor. Os artigos abordavam questôes envolvendo: desenvolvimento infantil, saúde, alimentação, educação sanitária, dicas de atividades e materiais, relatos de experiências, bem como respostas a cartas enviadas à redação da revista. Este informativo foi publicado pelo MOBRAL até 1986, após esta data sua publicação ficou a cargo da Secretaria de Ensino Básico. A característica marcante das publicaçôes de 1982 a 1986 é a simplicidade dos textos, que apenas informam o monitor, de maneira simplista e simplificada, a respeito de como conduzir melhor o seu trabalho.

Esta publicação gira em torno da criança: como ela é, do que gosta, o que pensa, como cresce, seu ambiente, saúde, alimentação e necessidade. 
Nossa maior preocupação é discutir esses assuntos, procurando apóia-lo nas atividades diárias desenvolvidas com as crianças: jogos, histórias, desenho, pintura etc. Como o envolvimento das famílias é muito importante na pré-escola, alguns artigos estarão relacionados ao trabalho que você realiza com elas, para que possam não só compreender o que é feito com seus filhos, como também participar desse trabalho. (MOBRAL, 1982, p. 2)

Os textos não possuem nem ao menos referência bibliográfica e não há indicações de leituras. Não existia preocupação em teorizar muito os assuntos expostos. A tônica dos artigos figurava sempre entre organização do dia-a-dia, organização e participação da comunidade, questôes de saúde (combate e prevenção de doenças, tais como: sarna, sarampo etc.), sugestões de atividades e materiais, principalmente fabricados a partir de sucatas. A seção que atendia às cartas das leitoras demonstrava claramente a visão estereotipada dos monitores em relação às crianças com as quais trabalhavam, que eram crianças pobres. Suas cartas eram pedidos de conselhos de como lidar com os problemas decorrentes da pobreza da população que atendiam. A contracapa destas revistas sempre continha uma história em quadrinhos que acabava por representar os preceitos veiculados a respeito da figura do monitor e de como este deveria conduzir o processo educativo.

O primeiro número da revista, publicado em 1983, possui como artigo incial "Vivemos em grupo... vivemos em comunidade", de Nancy Bezerra Batista e Natália Ursulina Batista. Este artigo apresenta o centramento do trabalho educacional a ser realizado na comunidade. Para fazê-lo, as autoras congregam as monitoras a seguirem o exemplo de Vanda, monitora que resolveu problemas da sua unidade pré-escolar juntamente com os pais das crianças:

Vanda foi treinada no Programa de Educação Pré-Escolar, e irá atender, diariamente, a 25 crianças de 4 a 6 anos. O bairro onde Vanda trabalha é muito pobre. A Comissão Municipal do MOBRAL de sua cidade conseguiu uma sala bem ampla, pertencente à paróquia, para ali iniciar as atividades educativas com as crianças. A sala, apesar de grande, estava suja, com algumas telhas quebradas. Nela se prepararia a merenda que o Instituto Nacional de Assistência ao Estudante - INAE - enviaria para a unidade. Vanda verificou que, sozinha, não teria condições de resolver tantos problemas. Visitou os pais das crianças, convidando-os para uma reunião. Na reunião, discutiu com eles a necessidade de segurança, 
O mobral e a educação de crianças menores de seis anos durante o regime militar...

higiene e alimentação das crianças. Procurou mostrar a eles, também, que aquele local iria servir de atendimento educativo aos seus filhos. Portanto, seria um local que pertenceria a toda a comunidade. Como melhorar a situação da "escolinha"? Alguns pais entenderam, outros não. Porém, aqueles que perceberam como era importante o que Vanda estava dizendo, resolveram ajudá-la. Seu Feliciano, pintor profissional, ser propôs a pintar a sala. Seu Zeca se ofereceu para consertar o telhado. Mas... e a tinta? E as telhas? E o tijolo e o cimento para construir a cozinha? Nesse momento, as mães sugeriram: "e se conseguíssemos algum brinde para fazermos uma rifa?". Outra lembrou: "Enquanto não temos dinheiro para construir a cozinha, será que não podemos nos revezar, preparando a merenda das crianças, em nossa própria casa?".

Deixamos para você pensar, monitor, o desfecho da experiência que viveu Vanda. (Batista \& Batista, 1983, p. 3)

O excerto não deixa dúvidas a respeito das condições materiais existentes nos locais utilizados para o atendimento das crianças, como também sobre qual o papel da comunidade nessa complexa cena de uma instituição educacional, cujo cotidiano é movido pelo baixo investimento financeiro. Não só a direção das unidades é chamada a se envolver com o trabalho, mas a comunidade e a própria monitora, ou seja, todos devem tomar as rédeas do atendimento. Destaca-se o seguinte relato de experiência publicado no segundo númeo da Revista, em 1983, intitulado "Quando a gente acredita, a gente faz!":

Aconteceu na Escola Efigênio Sales, da favela do morro do Capinzal, em Belo Horizonte, no ano de 1982. A diretora, muito preocupada com a saúde, o bem-estar e a alimentação de seus alunos, resolveu organizar com eles, num pequeno espaço de terreno, uma mini-horta. De lá, as próprias crianças colhiam couve, cebolinha, salsa, repolho, coentro etc. Além disso, para tornar a sopa das crianças mais nutritiva, teve uma idéia feliz: como a carne era "artigo de luxo", a diretora fez um trato com o açougueiro do lugar. Sempre que precisasse, iria ao açougue, para apanhar ossos com tutano e aparas de carne. Cozinhando-os, para fazer o caldo, e, depois, em vez de jogá-los fora, devolvia os ossos ao açougueiro, que os vendia a uma fábrica. Graças a isso, conseguiu que as crianças passassem a ter, na sopa, uma refeição nutritiva. (Lemos \& Bastos, 1983, p. 3)

A publicação da revista Criança condensa em suas páginas, enquanto esteve sob a tutela do MOBRAL, todos os princípios até aqui expostos, ou seja: incentivo ao trabalho voluntário, centramento na 
comunidade, espontaneísmo, precariedade do trabalho pedagógico e consequentemente do próprio atendimento. Cabe agora o seguinte questionamento: Qual o significado para o regime militar do trabalho realizado pelo MOBRAL, ou seja, o que ele exemplifica?

\section{Conclusão}

A expansão do atendimento pré-escolar realizado pelo MOBRAL funcionou para o regime militar no rol das políticas destinadas aos carentes como um paliativo ideológico eficaz. A educação pré-escolar foi encarada como a grande panacéia, a única saída para os problemas decorrentes do baixo nível de renda de pais e crianças, que tanto prejudicavam o processo educacional. Salvar-se-ia a escola com o atendimento às crianças pequenas, preparando-as para a primeira série e compensando suas inúmeras carências. Assim, as chances de sucesso individuais aumentariam e, portanto, a superação da condição de pobreza tornar-se-ia real. O regime, no ápice de sua crise, debatese para recompor a hegemonia, o controle social, e utiliza-se, para tanto, da educação, entre todos os níveis, em especial o pré-escolar. Infelizmente, as práticas cristalizadas pelo MOBRAL não passaram impunes pela história da educação de crianças menores de seis anos, porque referendaram o oferecimento de um atendimento de baixa qualidade, feito de qualquer jeito para as camadas populares, em detrimento da democratização da educação ofertada nesse nível às elites brasileiras, desde o século XIX. O discurso do MOBRAL, que acaba por defender e referendar o trabalho voluntário e traz junto com este o amadorismo e o espontaneísmo, congrega discursos presentes no passado recente do atendimento à infância brasileira e, prodigiosamente, lança seus dados para o futuro.

Do passado, retoma e perpetua preconceitos presentes na sociedade brasileira. Para ilustrar um pouco do que estamos falando, apresentarei a imagem de infância divulgada durante o Império brasileiro e sintetizada nas idéias do Barão de Macaúbas. ${ }^{8}$ Este, em suas obras, sintetizava a dubiedade do pensamento educacional da época, que transitava entre a religião e os ideais liberais. Mas, como a infância expressava-se, ganhava cores nos livros do Barão? A infância era apresentada por ele com paixão, mas sua devoção à educação da criança 
O mobral e a educação de crianças menores de seis anos durante o regime militar...

partia, segundo Valdez (2006, p. 224), de uma imagem clara de como essa deveria ser: "dócil, aplicada e digna."

Abílio, a exemplo de outros educadores desse período, desenvolvia uma pedagogia de cunho preventivo, cujo alvo era a criança pela sua própria característica, tida como "maleável”, se diferenciando da população adulta, miscigenada e portadora de maus hábitos, da candura da infância. O tão desejado progresso da civilização só poderia ser efetivado se viesse acompanhado do esforço moral e da religião, e a escola, colocada no papel de redentora da humanidade e salvadora dos males da ignorância, era o ambiente propício para esta realização. "Investir na infância, seja ela pobre ou rica, era o modo ideal para atingir os valores morais necessários para se chegar a uma sociedade civilizada" (Valdez, 2006, p. 224).

Portanto, a criança não portava o mal, mas era vulnerável a ele, por isso a educação deveria exercer o papel de vigilante e, ao mesmo tempo, de guia para que a infância brasileira se desenvolvesse da melhor forma possível. Assim, em seus livros, por meio de textos e ilustrações, o Barão ensinava e persuadia os pequenos a serem dóceis, educados, obedientes e a amarem os estudos.

Segundo Valdez (2006), Abílio queria ensinar às crianças as virtudes do trabalho, gerando o desprezo pela desonestidade, preguiça e vadiagem. A ociosidade e o vadiar, para o Barão, eram pecados sérios e todas as crianças, sejam ricas ou pobres, deveriam ser educadas para repudiá-los. Havia, por parte do Barão, uma intenção de modelar a infância brasileira:

(...) era preciso ensinar um código comum de comportamentos que fosse válido para todas as crianças, pois a infância era portadora de "pequenos defeitosinhos", como o autor registrou, sendo urgente moldar a cera enquanto mole, antes que fosse tarde. Desta forma, a frase "O que Joãozinho não aprende João não aprenderá jamais" se adequava perfeitamente aos seus preceitos de, quanto antes, intervir nessa formação, melhor o resultado. (Valdez, 2006, p. 245)

A prática pedagógica apresentada através dos manuais do MOBRAL também esta preocupada com a ordem e o progresso brasileiro. Contudo, sua dinâmica é diferente. Este progresso é colocado em perigo quando a criança menor fracassa na escola de primeiro grau. Como fazer 
para que ela fique na escola? A chave está na educação anterior ao período escolar, ou seja, no atendimento pré-escolar. Este atendimento, destinado às crianças pobres, parte da mesma premissa que a educação pensada pelo Barão, ou seja, precisamos intervir na formação das crianças o quanto antes. Ao fornecermos educação, prevenimos o possível fracasso futuro e garantimos sua formação inicial. A mesma lógica perversa que definia para o Barão a infância pobre como suscetível, ou melhor, destinada ao fracasso, caso não recebesse ajuda aparece presente aqui. $\mathrm{O}$ atendimento não se constitui em um direito da criança. Ele é, portanto, uma dádiva, uma chance a mais, justificando-se assim a não discussão de padrões mínimos de qualidade para o mesmo.

Ao final do século passado, após o regime militar e com alguns anos de experiência democrática no Brasil, assistimos à defesa novamente do voluntarismo na educação. Durante o ano 2000, ao se comemorar os 500 anos do Descobrimento do Brasil, a educação estava no ápice desta comemoração encampada pela Rede Globo de Televisão: o projeto "Brasil 500 anos" trazia a figura do professor como chave. Durante todo ano de 1999 fomos presenteados a cada mês com a escolha de um professor "modelo" que, quase sempre, era alguém que trabalhava em lugares isolados, com populações extremamente carentes, e fazia muito mais do que "ensinar", trazia "esperança" para aquela população, trazia a possibilidade de um "futuro melhor". Muito pouco este professor ensinava do "conteúdo escolar", pois ele geralmente dedicava-se a extrair a criatividade e o conhecimento que os alunos já possuíam. Um professor de História apresentado neste programa ilustra muito bem este fato: ele trabalhava em condiçóes precárias dentro de verdadeiros containeres apertados e superlotados, mas, apesar de tudo isso, este professor não "enchia" a cabeça dos alunos com coisas "arcaicas" de história, ele dava aulas diferentes, onde cada um descobria a sua própria história e da sua família ao mesmo tempo em que descobria que falar e escrever sobre sua história e ouvir a história de seus colegas é algo mais importante do que amontoados de fatos passados com outras pessoas, em outros tempos e em outros locais. Assim, a aula se tornava mais "criativa", "realista", "dinâmica" e "interessante".

Durante doze meses, as características principais do trabalho do professor de história foram sendo repetidas através da escolha de outros 
O mobral e a educação de crianças menores de seis anos durante o regime militar...

docentes: o trabalho em condições precárias e a busca dos conteúdos no cotidiano dos alunos. Esculpia-se aos poucos a figura do professor não como um profissional qualificado, que necessita de um ambiente equipado para o trabalho, mas como a de um missionário, que trabalha incansavelmente para educar os mais pobres, dando o pouco que possui, doando-se com amor e fé para que este país "vá pra frente". O ponto culminante desta campanha viria a ocorrer ao final do ano, com o incentivo ao trabalho voluntário na escola, afinal "Voluntário na educação é amigo da escola". Clama-se por mais pessoas dedicadas (pedreiros, juízes, padeiros, modelos, costureiras etc.) para que o professor possa dividir este trabalho lindo que ele e todo corpo técnico da escola realizam. A instituição educacional escola torna-se o lugar onde qualquer pessoa de boa vontade pode atuar, o ato de ensinar é algo simples e depende majoritariamente do querer de cada um e de um pouco de prática. Do contrário, como poderia uma modelo tornar-se uma "contadora de histórias", ignorando todos os estudos e pesquisas existentes a respeito da literatura infantil na escola? Este apelo voluntarista, centrado na participação da comunidade, como procuramos explicitar neste texto, poderia ganhar ares de novidade, mas não se constitui como tal. A expansão da educação de crianças menores de seis anos em nosso país, durante o regime militar, nos traz as conseqüências nefastas deste tipo de atendimento, tanto para a criança como para a imagem e carreira docente do profissional que com ela atua.

Hoje, início do século XXI, a educação de crianças pequenas vêse relegada ao papel de coadjuvante na formação humana do indivíduo. O profissional desse nível de ensino tem um trabalho hercúleo para ser reconhecido como tal, reconhecimento este que se reflete em salário e condições de trabalho dignas. A compreensão das marcas deixadas pela expansão realizada no regime militar nos auxilia a romper com práticas excludentes tomadas por naturais no cotidiano das instituições de educação infantil. Que mais pesquisas venham a nos auxiliar nesse trabalho que é, ao mesmo tempo, uma tentativa de reconstrução da história desse atendimento.

Recebido em novembro de 2007 e aprovado em julho de 2008. 


\section{Notas}

1. MOBRal: Movimento Brasileiro em Prol da Alfabetização, programa do governo federal iniciado em 1971, cujo objetivo era a erradicação do analfabetismo no Brasil, sendo extinto em 1985.

2. Germano (1993, p. 211 à 261) aponta o período que iniciou com o governo Geisel em 1974 e culminou com o término do governo do general Figueiredo, em 1985, como o longo e agonizante declínio do regime militar no Brasil. Caracterizando-se essa fase por: perda dos aliados civis da ditadura; fricçōes internas no bloco de poder; re-organização da sociedade civil, proporcionada pelo próprio regime que busca aliados civis; profunda crise econômica. Consequentemente, não se conseguia mais a hegemonia necessária para controle do tecido social brasileiro, na tentativa de posicioná-lo a favor da perpetualidade dos militares no poder. Segundo Germano (op. cit., p. 219), na "dialética da concessão e conquista”, a ambigüidade acaba por marcar todo esse período. A diferenciação, ainda segundo o autor, entre os objetivos proclamados pelo governo para as políticas públicas e as prioridades reais explicitadas nas açôes oriundas do regime nos revelam a contradição reinante no cerne do poder no momento.

3. Na década de 1980, baseado nos alicerces de 1970, durante o governo do general Figueiredo, é elaborado o III Plano Setorial de Educação, Cultura e Desporto (PSECD), de 1980, que destaca a importância da educação pré-escolar ao afirmar: "A educação pré-escolar é relevante, tanto pelo seu impacto pedagógico quanto pela possibilidade de influenciar as condições de nutrição, de saúde e de higiene das crianças e das famílias. A educação pré-escolar deve, portanto, ser entendida como aquela que se faz antes do ingresso no primeiro grau, independentemente do limite de idade, incluindo-se mesmo a ação sobre as gestantes. Tendo em vista que nos primeiros anos da inf ância se decidem, em grande parte, as potencialidades da personalidade humana, o impacto sobre a criança, a partir dos 7 anos de idade, pode estar já totalmente comprometido com um passado de desnutrição e de pobreza. Acresce, ainda, o fato de que o acesso ao pré-escolar, concentrado nas famílias ricas, acentua ainda mais a distância para com o aproveitamento escolar das crianças pobres" (Brasil, 1983, p. 12 e 13). A educação pré-escolar eleva-se, no III PSECD, à categoria de peça-chave para o sucesso do indivíduo na escola e em sua vida adulta.

4. Em conseqüência do III PSECD, em 1980, o MEC lança, através da Coordenadoria de Educação Pré-Escolar (coepre), as "Diretrizes de pré-escolar". Este documento traz como eixo do trabalho com a pré-escola a promoção do atendimento educacional, nutricional e sanitário, sendo que nenhum destes poderia faltar. O currículo e a metodologia deveriam ter como função preparar o aluno para entrar na primeira série do primeiro grau, contribuindo de forma efetiva para a queda dos índices de repetência. Contudo, a grande novidade destas diretrizes concentra-se nos recursos humanos. O documento reconhece a baixa qualificação e a atribui aos baixos salários: "este é um ponto crucial, pois sem uma remuneração adequada acreditamos que não adiantará investir em cursos de formação" (Brasil, 1980, p. 6).

5. É importante compreender que, quando se fala em educação pré-escolar nesse período, não se contempla o atendimento a crianças menores de 3 anos. As diretrizes de Planejamento do MEC (programação para 1983) assim definem como se dará o atendimento: "atendimento ao pré-escolar, com prioridade para a faixa-etária de quatro a seis anos, com ênfase em programas não-convencionais" (Brasil, 1983, p. 58).

Cad. Cedes, Campinas, vol. 28, n. 76, p. 379-403, set./dez. 2008

Disponível em <http://www.cedes.unicamp.br> 
O mobral e a educação de crianças menores de seis anos durante o regime militar...

6. A educação pré-escolar durante o regime militar assumiu a função de salvadora do ensino primário, a grande panacéia educacional, ou seja, ela reduziria os níveis de evasão e repetência, liberando o fluxo e permitindo que as crianças ficassem mais tempo na escola. Proporcionaria, ainda, uma melhora no nível social das famílias de baixa renda. Foi a década de 1970 que trouxe essa função de 'reparação' para a educação pré-escolar. A 'Teoria da Privação Cultural', que demandava um tipo de atendimento educacional a 'educação compensatória', chega ao Brasil aleardeando ter o resultado para o fracasso da educação brasileira nas primeiras séries. Segundo a teoria, os filhos de pais pertencentes às camadas mais pobres da população iriam naturalmente reprovar ou evadir da escola, porque possuíam uma série de "déficits culturais" e, já que seus pais não conseguiam educá-los adequadamente para permanecerem na escola, caberia a um nível anterior à escolarização formal compensar todas as carências e prepará-los para o ingresso no primeiro grau. O que, segundo Kramer (1992), trazia um significado novo para a pré-escola como uma ponte para ultrapassar barreiras sociais. "A abordagem da privação cultural se apóia no seguinte quadro conceitual: as crianças das classes populares fracassaram porque apresentavam 'desvantagens sócio-culturais', ou seja, carências de ordem social. Tais desvantagens são perturbaçōes, ora de ordem intelectual ou lingüística, ora de ordem afetiva: em ambos os casos, as crianças apresentam 'insuficiências' que é necessário compensar através de métodos pedagógicos adequados, se quer diminuir a diferença entre essas crianças 'desfavoráveis' e as demais, na área do desempenho escolar. A idéia básica é a de, através de intervenção precoce, reduzir ou eliminar as desvantagens educacionais" (Kramer, 1992, p. 32). O atendimento a crianças menores de 6 anos passa a ser orientado sob o triplo enfoque da educação compensatória: educação, saúde/nutrição e assistência social. Tal enfoque, segundo Rosemberg (1992), é absorvido pelo II Plano Setorial de Educação e Cultura do Brasil. Assim, a pré-escola ganha maior destaque e um relativo aumento em sua oferta, feita através da educação de massas, sem infra-estrutura adequada ou pessoas especializadas para este tipo de atendimento, e "em quase 50\% dos docentes tem apenas o primeiro grau completo e incompleto” (Ferrari, 1988, p. 69). Entretanto, no meio acadêmico, a discussão encaminhava-se para a superação dos enfoques aqui presentes e a busca de uma função que traduzisse a especificidade do atendimento a crianças menores de seis anos: "Nem inútil, nem capaz de resolver todos os problemas futuros, nem tampouco importante por si mesma, a pré-escola tem sim como papel social o de valorizar os conhecimentos, exercendo o que me acostumei chamar de função social pedagógica da pré-escola” (Kramer, 1987, p. 79).

7. Essa chamada à participação da comunidade efetua-se durante essa fase do regime, porque, segundo Germano (1993, p. 221-261), a crise no poder leva o grupo no poder ao apelo à sociedade civil e sua participação. Busca-se recuperar a hegemonia através da legitimação do regime: "De todo modo, a busca de legitimação conduz a uma mudança no discurso e na forma do relacionamento do Estado com as classes subalternas. Tal mudança possibilita a emergência de novos problemas, temas e metas potenciais na agenda do sistema político. Com efeito, a exclusão dos dominados - exclusão econômica, política e social - começa a ser revista nos planos oficiais. As questôes sociais, que foram despolitizadas e reduzidas a questões 'técnicas', começam a ser tratadas como questôes políticas. O discurso da 'segurança nacional', do 'combate ao comunismo e à subversão' e do 'crescimento econômico a qualquer preço' - mesmo à custa da concentração da ren$\mathrm{da}$ - cede lugar a um outro que enfatiza a 'integração social', o 'redistributivismo' e os apelos 'participacionistas". Esse discurso traduz-se nas medidas adotadas pelo governo para conter focos de pobreza, por meio da chamada da comunidade a atuar de forma participativa. Várias medidas são tomadas tendo os "carentes" como objeto das políticas sociais, dentre elas a educação. Os levantamentos feitos pelo MEC a época davam conta 
de que o pré-escolar, era privilégio de poucos e que os problemas cruciais da educação brasileira (evasão e repetência) não haviam sido resolvidos. O III Plano Setorial de Educação Cultura e Desporto (1980-1985) traduz muito bem esse discurso, apresentando a incorporação em seu texto das críticas sofridas pelo governo na tentativa de torná-lo diferenciado dos demais planos. Programas de caráter compensatório são instalados, como exemplo temos "O Programa Nacional de Açôes Sócio-Educativas e Culturais para o meio rural (Pronasec)" e o "Programa de Ações Sócio-Educativas e Culturais para as Populações Carentes (PRODASEC)”, ambos criados e inciados em 1980 pelo ministro da Educação Eduardo Portella, portanto, na mesma época em que o MOBRAL assume a educação de crianças menores de seis anos. Contudo, aqui se revela o caráter redistributivista e participacionista destas ações, pois não se visava alterar contundentemente a situação dos excluídos, mas sim utilizar-se de açôes que permitissem ao estado: "a) Baratear o ensino destinado aos 'carentes', ao optar pela educação não-formal, aligeirando a escolarização, utilizando-se dos precários espaços 'comunitários' e de profesores com preparo insuficiente (...); b) Constatar que as organizaçôes populares, ao abandonar o campo das reinvindicaçōes, passam a assumir o papel do Estado no ensino fundamental (cf. Melo, 1990), mediante convênvios estabelecidos com as Secretarias de Educação. Com isso, o Estado barateia os custos e se desobriga de financiar a educação fundamental; c) Exercer o papel de organizador e, ao mesmo tempo, controlador da insatisfação social. A organização popular é assim enquadrada dentro de limites claramente definidos: ela deve restringir-se a 'projetos destinados a satisfazer suas necesidades básicas', assinala um dos documentos do PRODASEC (...); d) Colocar sobre novas bases o relacionamento educação e trabalho. Aqui não se trata mais de formar uma força de trabalho para a indústria ou para o mercado formal, porém, fundamentalmente, 'para elevação dos níveis de produção e produtividade do setor informal, fortalecendo a criação de empresas (microempresas) e formas associativas'; aproveitamento de bens e serviços, existentes no local, 'necessários à implantação e funcionamento de projetos educacionais (material de construção, equipamentos, serviços de manutenção, merenda. etc) (...)” (Germano 1993, p. 256). Assim, o Estado, levando a cabo tais projetos, barateia o atendimento expandindo-o e atendendo aos anseios populares. Porém, ao fazê-lo, fornece uma educação compatível com o nível socioeconômico dessa população, ou seja, um atendimento pobre para o pobre.

8. Abílio César Borges nasceu na Vila de Minas do Rio de Contas, em 9 de setembro de 1824, na Bahia. Faleceu no Rio de janeiro em 1891. Segundo Saviani (2007), formado em Medicina pela Faculdade de Medicina do Rio de Janeiro, a exerceu enquanto profissão por muito pouco tempo nos sertôes da Bahia.

\section{Referências}

BATISTA, N. ; BATISTA, N. Vivemos em grupo... vivemos em comunidade. Criança, Brasília, DF, v. 1, n. 2, p. 3, 1983.

BRASIL. Ministério da Educação e do Desporto. Diretrizes do pré-escolar. Brasília, DF: MEC/COEPRE, 1980.

BRASIL. Ministério da Educação e do Desporto. Legislação e normas da educação pré-escolar. Brasília, DF: MEC/SE, 1979.

Cad. Cedes, Campinas, vol. 28, n. 76, p. 379-403, set./dez. 2008

Disponível em <http://www.cedes.unicamp.br> 
O mobral e a educação de crianças menores de seis anos durante o regime militar...

FERRARI, A. Evolução da pré-escola no Brasil no período de 1968 a 1986. Revista Brasileira de Educação, Brasília, DF, v. 69, n. 161, p. 5574, jan./mar. 1988.

FUNDAÇÃO MOVIMENTO BRASILEIRO DE ALFABETIZAÇÃO (MOBRAL). Criança, Brasília, DF, v. 1, n. 2, 1982.

FUNDAÇÃO MOVIMENTO BRASILEIRO DE ALFABETIZAÇÃO (MOBRAL). Vivendo a pré-escola. Rio de Janeiro: MOBral, 1982.

FUNDAÇÃO MOVIMENTO BRASILEIRO DE ALFABETIZAÇÃO (MOBRAL). Criança, Brasília, DF, v. 2, n. 3, 1983.

FUNDAÇÃO MOVIMENTO BRASILEIRO DE ALFABETIZAÇÃO (MOBRAL). Criança, Brasília, DF, v. 2, n. 4, 1983.

FUNDAÇÃO MOVIMENTO BRASILEIRO DE ALFABETIZAÇÃO (MOBRAL). Criança, Brasília, DF, v. 5, 1983.

FUNDAÇÃO MOVIMENTO BRASILEIRO DE ALFABETIZAÇÃO (MOBRAL). Tema para reflexão: ação comunitária a partir de uma unidade pré-escolar. Rio de Janeiro: MOBRAL, 1983.

FUNDAÇÃO MOVIMENTO BRASILEIRO DE ALFABETIZAÇÃO (MOBRAL). Tema para reflexão: educação. Rio de Janeiro: MOBRAL, 1983.

FUNDAÇÃO MOVIMENTO BRASILEIRO DE ALFABETIZAÇÃO (MOBRAL). Tema para reflexão: saúde e higiene. Rio de Janeiro: MOBRAL, 1983.

FUNDAÇÃO MOVIMENTO BRASILEIRO DE ALFABETIZAÇÃO (MOBRAL). Criança, Rio de Janeiro, v. 10, jun. 1984.

FUNDAÇÃO MOVIMENTO BRASILEIRO DE ALFABETIZAÇÃO (MOBRAL). Criança, Rio de Janeiro, v. 13, ago. 1985.

FUNDAÇÃO MOVIMENTO BRASILEIRO DE ALFABETIZAÇÃO (MOBRAL). Criança, Rio de Janeiro, v. 14, out. 1985.

FUNDAÇÃO MOVIMENTO BRASILEIRO DE ALFABETIZAÇÃO (MOBRAL). Criança, Rio de Janeiro, v. 18, nov. 1988.

HOBSBAWN, E. Sobre a história. São Paulo: Cia das Letras, 1998. 
KRAMER, S. O papel social da pré-escola. Caderno de Pesquisa, São Paulo, n. 58, p. 77-81, ago. 1985.

KRAMER, S. A politica do pré-escolar no Brasil. 4. ed. São Paulo: Cortez, 1992.

LE GOFF, J. História no cotidiano. In: Aries, P.; Duby, G.; Le GofF, J. (Org.). História e nova história. Lisboa: Teorema, 1994.

LEMOS, M.; BASTOS, A. Quando a gente acredita, a gente faz! Criança, Brasília, DF, v. 1, n. 2, p. 3, 1983.

MARX, K. O 18 Brumário e cartas a Kugelmann. 6. ed. Rio de Janeiro: Paz \& Terra, 1997.

MARX, K.; ENGELS, F. A ideologia alemã. 9. ed. São Paulo: Hucitec, 1993.

ROSEMBERG, F. A educação pré-escolar brasileira durante os governos militares. Cadernos de Pesquisa, São Paulo, n. 82, p. 21-30, ago. 1992.

SAVIANI, D. O debate teórico e metodológico no campo da história e sua importância para a pesquisa educacional. In: SAVIANI, D.; Lombardi, J.; Sanfelice, J.L. História e história da educação. Campinas: Autores Associados; HISTEDBR, 1998.

SAVIANI, D. História das idéias pedagógicas: reconstruindo o conceito. Caxambu: ANPEd, 1999. (mimeo.).

VAINFAS, R. Micro-história: os protagonistas anônimos da história. Rio de Janeiro: Campus, 2002.

VALDEZ, D. A representação de infância nas propostas pedagógicas do Dr. Abilio César Borges: o Barão de Macaúbas (1856-1891). 2006. Tese (Doutorado) - Faculdade de Educação, Universidade Estadual de Campinas, Campinas. 